\title{
Plastic Industry and World Environmental Problems
}

\author{
Shanty Oktavilia ${ }^{1 *}$, Mita Hapsari $^{1}$, Firmansyah ${ }^{2}$, Andryan Setyadharma ${ }^{1}$, Indah Fajarini Sri \\ Wahyuningsum $^{1}$ \\ ${ }^{1}$ Faculty of Economics, Negeri Semarang University, Semarang-Indonesia \\ ${ }^{2}$ Faculty of Economics and Business, Diponegoro University, Semarang-Indonesia
}

\begin{abstract}
The problem of managing plastic waste is the focus of the entire world today. Mismanaged plastics make a significant contribution to the increase in carbon emissions as a result of the release of plastic chemicals that are exposed to sunlight or are burned. The plastics industry which continues to experience an increase in production makes plastic waste continue to increase from year to year. This study aims to determine the relationship of the effect of the amount of plastic production on increasing the amount of $\mathrm{co} 2$ emission carbon at the global level using a simple linear regression analysis tool. The results showed that the production of plastics had a positive and significant effect, which meant that the higher the plastics produced by the plastics industry, the higher the amount of $\mathrm{CO} 2$ emission carbon. Similarly, the GDP per capita variable, showed positive and significant results. this means that the income pattern of the world community still has a positive effect on environmental degradation.
\end{abstract}

\section{Introduction}

Plastic waste is an environmental crisis faced by almost all countries in the world. Plastic is long-lived, soft, and difficult to be decomposed naturally by nature. Plastic has been produced since the 1950s and plastic waste is estimated to have reached 8 billion tons and is increasing every year [1]. The treatment of plastic waste is difficult and the processing also causes consequences for the environment. Some opinions state that plastic causes problems for the environment since it is produced in an industry, until when it becomes waste because it is difficult to decompose [2]. Nevertheless, the plastic industry is growing due to high public demand. Increased production will encourage economic growth. Plastic demand is high because the product is used mass in the community. However, pollution management caused by plastics is one of the challenges that must be overcome by all countries with relatively low environmental standards, especially in Asia, which is the largest contributor of plastic waste in the world.

Plastic production in the last few years began to shift to Asia. According to the study of Jambeck et al [2] the 20 countries that are ranked top based on the amount of mismanaged plastic waste are dominated by Asian countries. The biggest mismanaged plastic problem is

\footnotetext{
*Corresponding author: oktavilia@mail.unnes.ac.id
} 
China, which is 27.7 percent. The country is the largest plastic producer which contributed to the world's polyurethane and thermoplastic production in 2015 [3]. As a plastic producing country, China also contributes the largest $\mathrm{CO} 2$ of greenhouse gas emissions in the world as well as the biggest contributor to plastic waste in the sea with a low recycling rate [4]. The second rank is Indonesia, which is 10.1 percent of problematic plastic waste dumped into the Indonesian oceans. Plastic waste dumped into the sea reaches 187.2 million tons per year. Another problem is that the Asian sea region is a place for disposing of plastic waste from countries in the European region. Asia is one of the export destinations for plastic waste originating from Europe which has a level of consumption of plastic per capita far above the global average without handling environmentally friendly plastic waste.

Plastic production data as summarized in figure 1 shows an increase in global plastic production, measured in tons per year, from 1950 to 2015. In 1950 the world only produced 2 million tons per year. Since then, annual production has increased nearly 200 -fold, reaching 381 million tons in 2015 . For the context, this is roughly equivalent to the mass of two-thirds of the world's population. The decline in production that occurred in the 2009 and 2010 periods was caused by the effects of the 2008 global financial crisis - this is evident from the data contained in Figure 1[5].

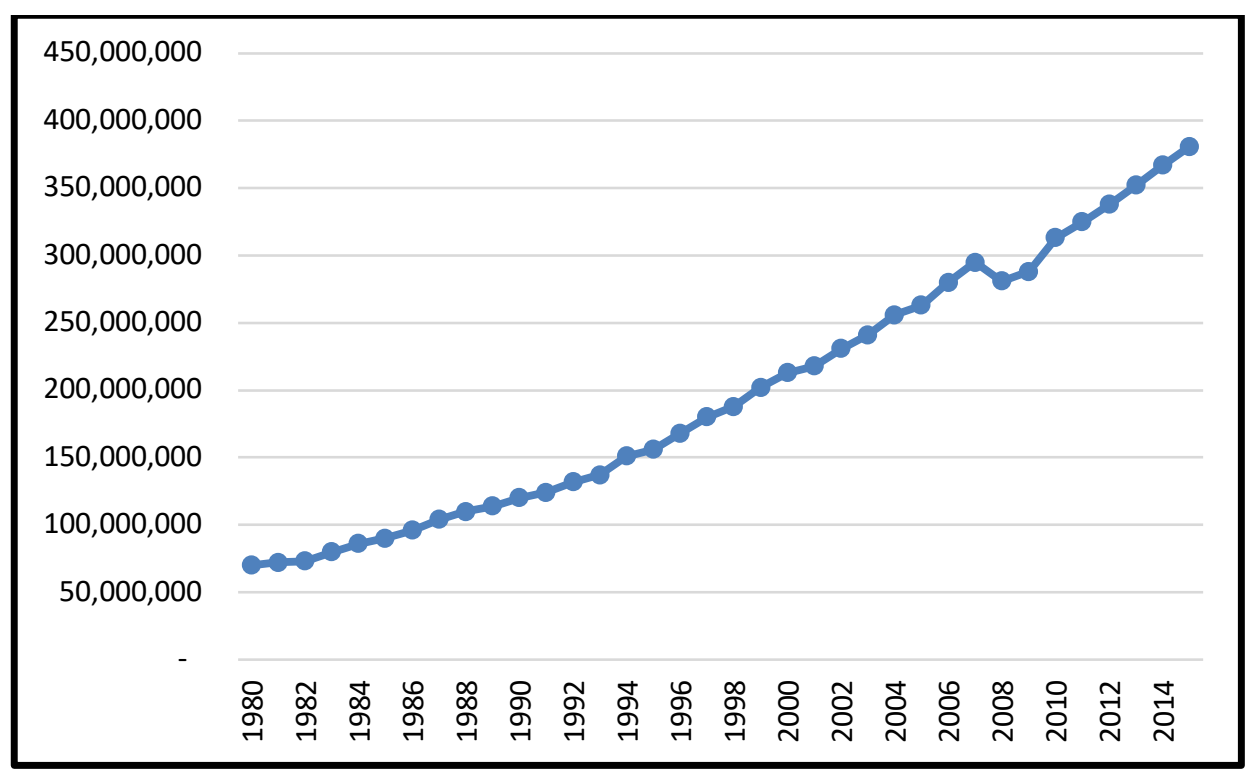

Fig. 1. Primary plastic waste generation (million tonnes)[5]

Plastic waste disposal methods prior to 1980 were carried out by burning and ignoring recycling. Recycling of plastic waste began propagating in the 1990s. During this period the increasing trend of plastic waste recycling reached an average of about 0.7 percent per year $[2,3]$. In 2015 an estimated 55 percent of global plastic waste was dumped into the sea, 25 percent burned and 20 percent recycled. If this trend continues to increase until 2050 then waste burning will decrease to 50 percent, recycling will increase by 44 percent and waste disposal will decrease to 6 percent [5]. However, this will not happen if there is no intervention by the vanguard in waste management. The government in each country needs to act decisively to reduce the use of plastics in the country because the industry does not want to lose the existence of this policy and reduce the profit from its production. The following Figure 2 is the primary plastic production data by industry sector: 


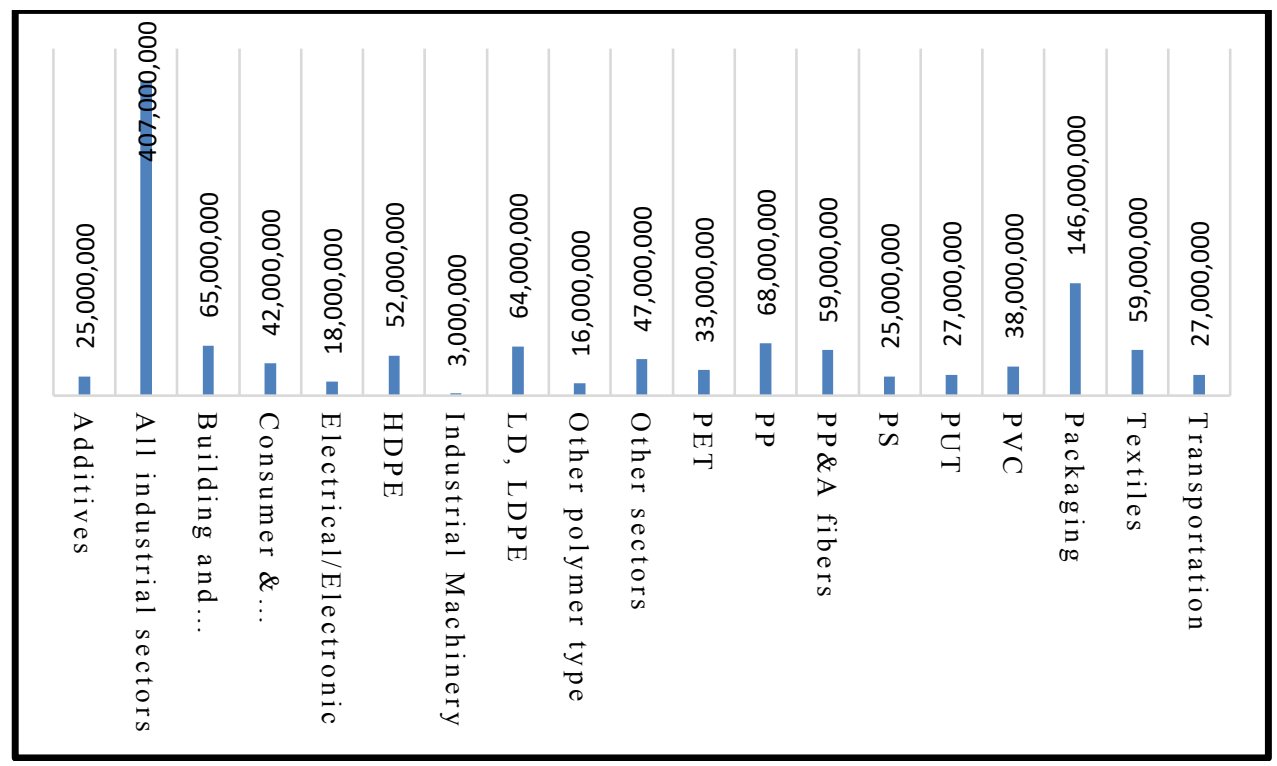

Fig. 2. Primary plastic production by industrial sector, 2015[5]

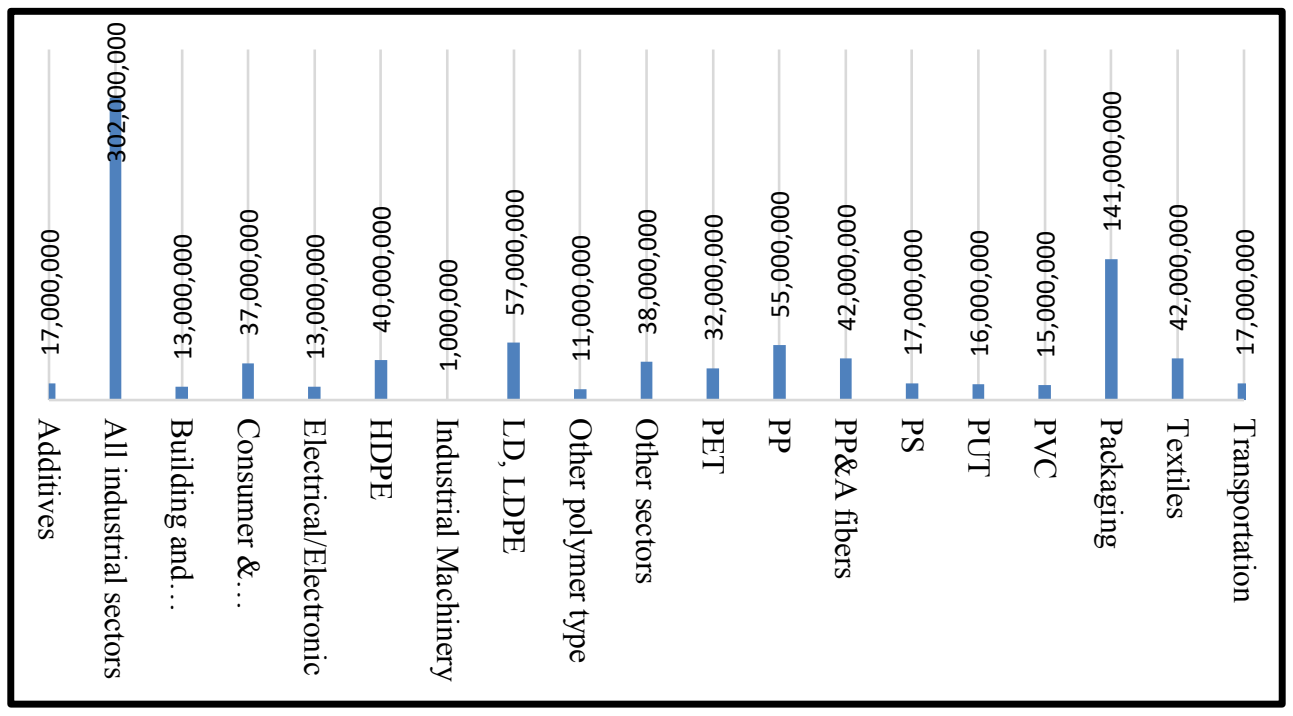

Fig. 3. Primary plastic waste generation (million tonnes)[5]

The allocation of plastic production by sector with 2015 data sources shows that the packaging sector is the dominant use of primary plastic (42 percent). The second rank is the building and construction sector (19 percent of the total). Primary plastic production does not directly reflect the amount of plastic waste generated in economic activities. This is also influenced by the type of polymer and the lifetime of the final plastic product. Primary plastic production based on the type of polymer can be found in figure 3 . 


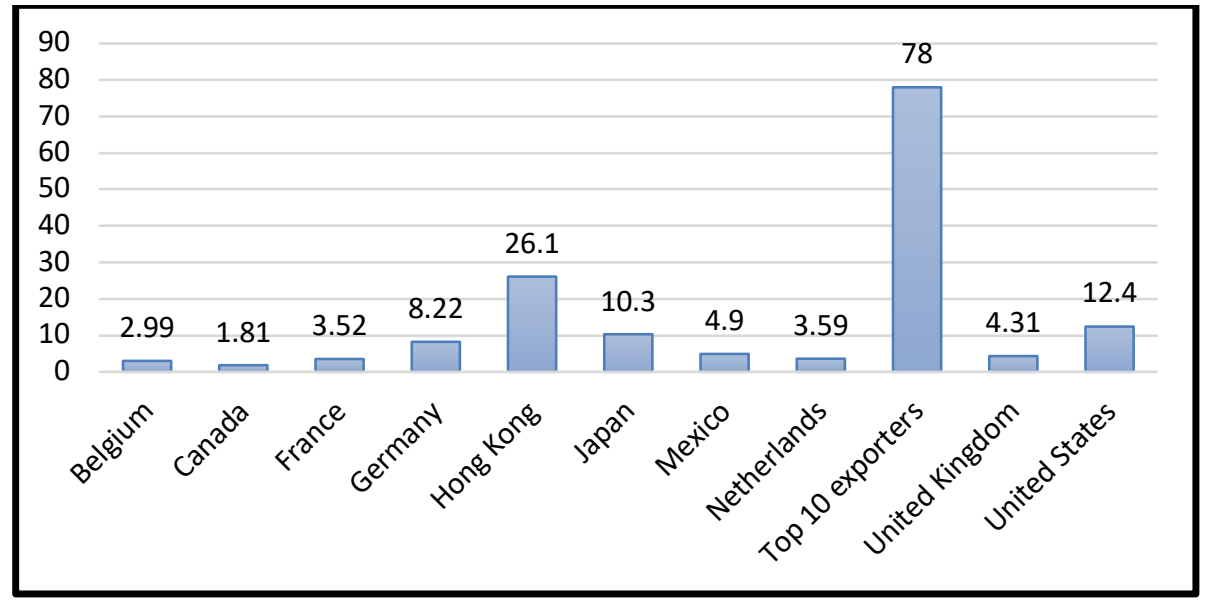

Fig. 4. Share of cumulative plastic exports over the period 1988 to 2016 by the top ten exporting countries.

The use of primary plastics by sector; Figure 4 shows the same sectors in terms of plastic waste generation. The making of plastic waste is greatly influenced by the use of primary plastics, but also the life of the product. Packaging, for example, has a very short service life to use (usually around 6 months or less). This is different from building and construction, where the use of plastic has an average age of 35 years. Under these conditions, packaging is the dominant producer of plastic waste, with the largest proportion of plastic waste sources. The latest data in 2015, showed primary plastic production was 407 million tons and around three quarters (302 million tons) ended up as waste.

The packaging industry seems to dominate the industry with plastic raw materials. This is also driven by an increase in the overall industrial sector that requires packaging in various types, for example the food and beverage industry, the clothing industry, and other industries that use plastic as packaging. The data shows that the manufacture of plastic waste is dominated by the packaging industry sector.

The packaging industry sector has the highest contribution in producing primary plastics that will be consumed by the community and will produce plastic waste, so the packaging industry is responsible for almost half of the total global plastic waste production. Wrong handling of plastic waste will lead to worse environmental degradation such as plastic burning or plastic disposal at sea. Plastics that are left exposed to sunlight or are burned can emit methane and ethylene gas and carbon which are said to be the main causes of climate change according to experts. In recent years the use of plastic has been in the spotlight for environmentalists including the United Nations agency. There are also findings of fact piles of mismanaged plastic waste in the Pacific Ocean that threaten the life of marine ecosystems [6]. Based on this background, this study aims to analyse the effect of plastic production in the world on environmental quality in the world. The quality of the environment is analysed by using the variable amount of greenhouse gas pollution, which shows the more greenhouse gases, the worse the quality of the environment. This study also tries to analyse the effect of income behaviour of economic actors in the world that are identified by using world GDP per capita. 


\section{Method}

The plastic industry in this study is represented by world plastic production variables. This research uses a regression econometric model with two independent variables, namely the amount of plastic production (plastic) and world income per capita (GDPcap). Environmental quality is approached by the use of variable greenhouse gases (GHG). Net GHG removals refer to changes in the atmospheric level of all greenhouse gases caused by forest change and land use activities, but also include the following: (a) $\mathrm{CO} 2$ emissions and removals from decreasing or increasing biomass stocks due to forest management, logging, collection firewood, etc .; (b) Conversion of existing forests and natural grasslands to other land uses; (c) Elimination of $\mathrm{CO} 2$ from the abandonment of previously managed land (eg agricultural land and grasslands); and (d) Emissions and $\mathrm{CO} 2$ emissions in the soil associated with land use change and management. GHG data used in millions of metric tons. The data used are secondary data sourced from World Bank / Key Indicators publications and Our World in Data (http://ourworldindata.org).

Regression models use time series data with a range of 1980-2015. The annual data used is relatively late, because the available environmental data often experiences a lagging update every year. However, this research is at least able to show the influence of the plastic industry in the world in contributing to the deteriorating environmental quality due to increased pollution. The empirical model used in this study is the ordinary least square regression model with a logarithmic model:

$$
\log G H G_{t}=\log \text { plastic }_{t}+\log \text { SDPcap }_{t}+e_{t}
$$

The regression model of this study is carried out by taking into account the results of testing the assumptions of the classical model and then analyzing the level of significations and goodness of fit through statistical measures. Furthermore, the results of the analysis are interpreted primarily with regard to the suitability of the results and hypotheses

\section{Result and Analysis}

Production of the plastic industry that increases every year raises the potential for enormous environmental pollution. The transmission of the amount of plastic input to the natural environment and the world's oceans can be approached from several aspects, including: First the elements of the plastic production used. The second is the distribution of plastic products from producers to end consumers and waste management chains. This is very important, not only in understanding the scale of the problem but also in implementing the most effective interventions for mitigation [2].

After the empirical model is conducted multicollinearity test shows there is no correlation between collinearity between independent variables in the empirical model. The results of multicollinearity test in the study showed that the model is free from the classical assumption problem of multicollinearity. Table 1 shows the cantered VIF values of less than 10 . 
Table. 1 Multicollinearity Test: VIF

\begin{tabular}{|c|c|c|c|}
\hline Variable & $\begin{array}{c}\text { Coefficient } \\
\text { Variance }\end{array}$ & $\begin{array}{c}\text { Uncentered } \\
\text { VIF }\end{array}$ & $\begin{array}{c}\text { Centered } \\
\text { VIF }\end{array}$ \\
\hline LOG(PLASTIC) & 0.001516 & 10577.93 & 7.981178 \\
\hline LOG(GDPCAP) & 0.011485 & 19188.93 & 7.981178 \\
\hline C & 0.160913 & 3118.147 & NA \\
\hline
\end{tabular}

The empirical model has also been freed from the heteroscedasticity test which aims to test whether in the regression model there is an inequality of variance from the residuals of one observation to another. White test results show the Chi-Square Probability is greater than 0.05 which states there is no heteroscedasticity in the empirical model (Table 2).

Table. 2 Heteroskedasticity Test: White

\begin{tabular}{|l|r|l|r|}
\hline F-statistic & 1.824283 & Prob. F (5,30) & 0.1382 \\
\hline Obs*R-squared & 8.393638 & Prob. Chi-Square (5) & 0.1358 \\
\hline Scaled explained SS & 4.795740 & Prob. Chi-Square (5) & 0.4413 \\
\hline
\end{tabular}

Table. 3 Autocorrelation Test - Breusch-Godfrey Serial Correlation LM Test

\begin{tabular}{|l|l|l|l|}
\hline F-statistic & 2.193701 & Prob. F $(2,31)$ & 0.0833 \\
\hline Obs*R-squared & 10.13296 & Prob. Chi-Square (2) & 0.0716 \\
\hline
\end{tabular}

The test results of the assumption of the classic autocorrelation model also indicate if the empirical model is free from the autocorrelation problem. This can be seen from table 3 . Autocorrelation Test - Breusch-Godfrey Serial Correlation LM Test which shows the probability of chi-square is greater than 0.05 , so it states there is no autocorrelation in the empirical model.

The results of data processing using simple linear regression indicate the two independent variables influence according to the hypothesis. World plastic production has a positive and significant effect at $\alpha 5 \%$. This is indicated by the value of $t$ statistic that is greater than $t$ table or indicated by a probability number $<5$ percent. This is also the case with the statistical $t$ numbers and probabilities of world income per capita variables, which show a positive and significant effect. In addition to the statistics, the analysis also shows an R2 of 0.9407 . This means that the variation of the independent variable can explain the behaviour of the dependent variable by 94.07 percent and the remaining 5.93 percent is explained by variables outside the empirical model

Table.4 Estimation Output

\begin{tabular}{|c|r|r|r|}
\hline Variable & Coefficient & t-Statistic & \multicolumn{1}{c|}{ Prob. } \\
\hline LOG(PLASTIC) & 0.187724 & 4.822101 & 0.0000 \\
\hline LOG(GDPCAP) & 0.365351 & 3.409125 & 0.0017 \\
\hline C & 12.82403 & 31.96896 & 0.0000 \\
\hline
\end{tabular}

Looking at the effect of GDP per capita on greenhouse gases (GHG), this study is consistent with the Kuznet Curve phenomenon, which occurs in income behaviour in influencing the global environment. This research is in accordance with the results of several previous studies, among others [7-9], which states that overall, in the world, an increase in per capita income encourages an increase in environmental quality. The magnitude of the effect of increasing world income per capita by 1 percent, causing an increase in greenhouse gases by 0.36 percent.

The plastic industry in this study was identified as contributing to increasing environmental degradation. An increase of 1 percent of plastic production has an effect on the increase in greenhouse gases by 0.18 percent. The results of this study are consistent 
with several research findings that use plastic industry data and plastic waste to influence environmental degradation in several locations, including Lin \& Nakamura [4], Mani \& Singh [10] and Mwanza \& Mbohwa [11].

The limitation of this study is that the data does not update quickly, but research using plastic production and exploring the world's plastic waste as a contributor to environmental degradation needs to be updated. The research method uses the OLS regression model which shows a long-term relationship model of influence between variables. In environmental research, interdependence between variables is also long-term, so the OLS method is still relatively feasible to use to answer research problems.

\section{Conclusion}

Based on the research results above, it can be concluded that there is a positive and significant influence between global plastic production on carbon emissions. This means that the higher the level of global plastic production, the higher the carbon emissions of $\mathrm{CO}_{2}$ and the greenhouse gas (GHG), in other words the production of plastics indirectly also contributes to the increase in carbon dioxide emissions from plastic waste that is generated from daily consumption. Increasing industrial growth is marked by an increase in per capita income of citizens. This research proves that the income per capita of the world's population has an effect on increasing greenhouse gases in the world.

Suggestions for governments, both international governments and governments in each country, to be able to synergize with other stakeholders, namely the private sector and the community as a whole in managing the environment properly and taking into account the values and principles of sustainable environment. In this case the governments of the countries of the world who are members of the United Nations have a major role in building good environmental governance. The UN through various environmental organizations underneath invites its member countries to participate in building good and environmentally friendly environmental governance. Implementation of the 3R (Reduce, Reuse, Recovery) policy in all countries in the world as an effort to deal with the problem of plastic waste which has a great influence on the environment.

\section{Reference}

1. UNEP, State Plastics World Environment Day Outlook, https://www.unenvironment.org/resources/report/state-plastics-world-environmentday-outlook-2018, (2018)

2. Jambeck, J.R., Geyer, R., Wilcox, C., Siegler, T.R., Perryman, M., Andrary, A, Narayan, R., Law, K.L., Plastic waste inputs from land into the ocean. Science, (September 2014), 1655-1734. (2014)

3. Dauvergne, P. Why is the global governance of plastic failing the oceans? Global Environmental Change, 51(May), 22-31. (2018)

4. Lin, C., \& Nakamura, S. Approaches to solving China's marine plastic pollution and CO2 emission problems. Economic Systems Research, 31(2), 143-157. (2019).

5. Our World in Data, Plastic Pollution Datahttps://ourworldindata.org/plastic-pollution

6. Koop, S. H. A., \& van Leeuwen, C. J. The challenges of water, waste and climate change in cities. Environment, Development and Sustainability, 19(2), 385-418. (2017).

7. Baranzini, A., Weber, S., Bareit, M., \& Mathys, N. A. The causal relationship between energy use and economic growth in Switzerland. Energy Economics, 36, 446-470 (2013). 
8. Ghosh, S. Examining carbon emissions-economic growth nexus for India: A multivariate cointegration approach. Energy Policy, 38, 2613-3130 (2010).

9. Oktavilia, S. \& Firmansyah. The Relationships of Environmental Degradation and Trade Openness in Indonesia. International Journal of Economics and Financial Issues, 6(S6) (2016).

10. Mani, S., \& Singh, S. Sustainable Municipal Solid Waste Management in India: A Policy Agenda. Procedia Environmental Sciences, 35, 150-157. (2016).

11. Mwanza, B. G., \& Mbohwa, C. Drivers to Sustainable Plastic Solid Waste Recycling: A Review. Procedia Manufacturing, 8(October 2016), 649-656. (2017). 